\title{
Palliative care patients' perceptions of the work involved in understanding and managing the network of care provision surrounding them
}

\author{
N Jarrett, ${ }^{1}$ K Porter, ${ }^{1}$ C Davis, ${ }^{2}$ J Lathlean, ${ }^{1}$ S Duke, ${ }^{1}$ J Corner, ${ }^{1}$ \\ $\mathrm{J}$ Addington-Hall ${ }^{1}$
}

${ }^{1}$ Faculty of Health Sciences, University of Southampton, Southampton, UK

${ }^{2}$ Countess Mountbatten House, Moorgreen Hospital and University Hospital Southampton NHS Foundation Trust, Southampton, UK

\section{Correspondence to} Dr Nikki Jarrett, Centre for Innovation and Leadership in Health Sciences, Faculty of Health Sciences, University of Southampton, Highfield, Southampton, Hants S017 1BJ, UK; nj1@soton.ac.uk

Received 25 August 2014 Revised 17 February 2015 Accepted 11 March 2015
To cite: Jarrett N, Porter K, Davis C, et al. BMJ Supportive \& Palliative Care Published Online First: [please include Day Month Year] doi:10.1136/bmjspcare-2014000781

\section{ABSTRACT}

Objective To explore the work carried out for cancer palliative care patients in understanding and dealing with the often large network of care provision surrounding them.

Method Qualitative thematic analysis of interviews with 24 patients (aged 48-85 years) with 15 different types/sites of cancer and palliative care needs.

Results The main theme of 'patient work-their strategies and project management' is presented. Subthemes included: being organised and keeping records; planning ahead and coordinating care; information gathering; understanding the hierarchy and knowing who the key people are; strategies to remember names and roles; understanding and 'working the system'. Insights are given into the work carried out on patients' behalf by family, although it was unclear who would do this work if no family was available. Some of the challenges faced by patients and families are identified. These included limited information; uncertainty when care is transferred between different teams or locations; deciding who to contact and how; and negotiating through gatekeepers.

Conclusions The number and variety of people contributing to the care of a cancer palliative care patient can be difficult for patients and family to comprehend. Work is required by patients or family on their behalf to achieve the level of understanding required to become accomplished at navigating the system and project managing their care organisation, and is probably influenced by role expectations and previous experience. Much of this additional, often hidden, workload for patients and family could probably be reduced with clear, timely information provision by health professionals.

\section{BACKGROUND}

People with cancer palliative care needs often experience treatments, care and monitoring in different locations, involving numerous health and social care professionals (HSCPs). ${ }^{1}{ }^{2}$ Multidisciplinary working is acknowledged as good practice in cancer palliative care and end-of-life care ${ }^{3}$ this is often credited with improved outcomes ${ }^{4}$ and effective team working is recommended. ${ }^{5} 6$ Cancer palliative care management can be described as situated within a 'system of relationships', including relationships within families, between patients and HSCPs, and among HSCPs. ${ }^{7}$

Failures in communication, coordination and continuity of care across service interfaces $^{8} 9$ and between HSCP can be sources of difficulty ${ }^{10}$ with potential costs in economics, ${ }^{11}$ disease diagnosis ${ }^{12}$ and patient outcomes. ${ }^{13-15}$ Good communication and continuity facilitate optimal care, ${ }^{16}$ positive health outcomes ${ }^{17}$ and patient satisfaction. ${ }^{18}$ The extent and quality of transfer of information between and among HSCP is important. Some patients and/or families take on an active role in transporting information, ${ }^{19}{ }^{20}$ but can be hindered by a lack of clarity, ${ }^{21}$ increasing the work burden for patients ${ }^{22}$ and families. ${ }^{18}$ The importance of improving communication and continuity of care in cancer and palliative care has been recognised. ${ }^{23-28}$

Efforts to improve communication continuity in cancer palliative care will fail unless these are understood from the perspective of patients. Little is known about cancer palliative care patients' perceptions 
and understanding of the complex care network surrounding them and importantly, their involvement (or not) in helping to manage and make sense of it. This paper reports findings from an interview study in southern England that explored these issues.

\section{METHODS}

National Health Service (NHS) ethical approval and permissions were obtained [REC (Berkshire) reference number: 10/H0505/51]. Potential patient participants who met the inclusion criteria (see box 1) were identified by HSCPs who gave them an information sheet $(n=71)$.

Information packs were given to patients who expressed an interest $(n=33)$ and appointments were made with patients who wanted to take part $(n=24)$. Prior to the interview, full written consent was obtained.

Twenty-four patients 48-85 (mean 67) years of age participated. Nine were male and 15 were female. All patients had palliative care needs by virtue of the inclusion criteria, but varied in terms of cancer site, time since cancer diagnosis ( 2 weeks to 5 years), time to death, previous and continuing treatments or care.

Each patient participated in one interview (range $28-169$, mean $65 \mathrm{~min}$ ) carried out in a location convenient for the patient. An interview schedule (see table 1), devised around the project aims, guided the interview, although the researcher was flexible to respondents' needs and issues. The patient described

\section{Box 1 Patient inclusion criteria}

Patients will be potentially eligible to take part in the study who meet all of the following inclusion criteria:

$>$ Have cancer

- Receiving care from the hospital palliative care team and/or from the specialist palliative care unit facilities including day, inpatient, outpatient, and community care and/or are on Gold Standards Framework (GSF) registers as 'likely to be in the last year of their life'

- Resident within the geographical region covered by the hospital trust

- Have capacity to provide informed consent (in the health and social care professional's (HSCP) judgement)

- Are at least 18 years of age

- Are able, either by themselves or through a representative (eg, a family member, friend or translator) acting as an interpreter or proxy interviewee, to communicate in English with the researcher

- Are able, in the opinion of their HSCP, to cope, physically and emotionally, with the research procedures and understand that they have cancer, and are able to talk about this with the researcher everyone 'involved in their care' (including HSCP, lay persons and family members), which was drawn by the researcher as a spider-gram of their care network, providing context for the subsequent interview.

Interviews were transcribed and anonymised. Analysis was carried out using Atlas.ti to aid management of the textual data. Initially each transcript was read and open codes assigned. Larger themes and subthemes were identified in line with the project aims and definitions agreed on. All interviewing, transcription checking and analysis was carried out by KP in consultation with NJ. Provisional themes, concepts and example quotations were presented for discussion and refinement at the project team meetings that included coauthors, clinicians, patients and carers.

Selected quotes illustrate issues raised by participants in their own words. In making the selection, the intention has been to present clear examples drawn from a range of participants. Quotations have been edited to reduce their length, aid clarity or remove identifying information. Missing text is indicated by ellipses. Contextual patient information is offered to add relevant depth, but comprehensive details are not given to preserve anonymity.

\section{RESULTS}

Patients were asked about their knowledge, own involvement in and understanding of the care network and communication surrounding them. Analysis was guided by the project aims and so a core theme concerned this activity and has been labelled 'patient work-involvement, strategies and project management'. Table 2 illustrates this theme and its subthemes with descriptive examples.

As can be seen in table 2, many patients were active in terms of managing and coordinating care within their network. Some patients and family carers appeared to have a good understanding of the system and communication processes, often acquired through experience, and were able to facilitate more seamless care communication and coordination. Work coordinating their care, although taking time and effort, could reduce overall burden as illustrated here-

I had to go get an X-ray...have a blood test...see the doctor...all separate days... [wife] rang up the hospital, and, rearranged to do it all on the same date...so we did exactly the same as that the following time. (Patient 6)

Patient 6 and his wife, who did most of the organising on his behalf, had limited previous experience, but in the 7 months since the diagnosis have developed this useful approach to reducing travel, time and financial burden.

Effort put into gaining the necessary information and understanding to achieve this was salient. Most patients (20 out of 24) described strategies for gathering information on who was involved in their care. 


\begin{tabular}{|c|c|}
\hline Topic area & Example questions, prompts if required \\
\hline \multicolumn{2}{|l|}{ 1. Preamble and consent } \\
\hline 2. Mapping process & Patient identifies everyone involved in their care. (These data are not presented in this paper) \\
\hline 3. Interview questions & $\begin{array}{l}\text { Follow-up, explore and probe as appropriate; questions can be skipped, rephrased or explained as required; ask for } \\
\text { specific examples when possible }\end{array}$ \\
\hline Explore the network map & $\begin{array}{l}\text { For example- } \\
\text { Who is organising and managing communication about your care overall? } \\
\text { Explore different roles of people on the map in relation to communication (as appropriate) } \\
\text { Do you know who (this can be anyone, including you) has an overview of all this? } \\
\text { Does anyone oversee the communication in this map or know the 'big picture'? } \\
\text { Do you know if anyone is acting as what we could call a 'case manager', 'key worker' or a 'communication } \\
\text { manager' for you? }\end{array}$ \\
\hline $\begin{array}{l}\text { Explore perceptions and } \\
\text { experiences }\end{array}$ & $\begin{array}{l}\text { For example- } \\
\text { How do you find the experience of communicating with all these different people involved in your care? } \\
\text { Have you ever found it frustrating or difficult to communicate with someone involved in your care? If so, can you } \\
\text { tell me about a specific experience when this happened? } \\
\text { Have you ever found it easy or convenient to communicate with someone involved in your care? If so, can you tell } \\
\text { me about a specific experience when this happened }\end{array}$ \\
\hline Explore patient/family strategies & $\begin{array}{l}\text { For example- } \\
\text { Do you have any strategies or suggestions for how to improve the communication between yourself and the } \\
\text { people involved in your care? } \\
\text { Are there any communication tools that you use with the people involved in your care (ie, patient-held records, } \\
\text { patient care diary, information cards, etc) } \\
\text { Do you have any strategies or suggestions for how to improve the communication amongst the people involved in } \\
\text { your care? } \\
\text { What do you think hinders, or creates barriers to, good communication between yourself and the people involved } \\
\text { in your care/among those involved in your care? }\end{array}$ \\
\hline $\begin{array}{l}\text { 4. Wind down and demographic } \\
\text { questions }\end{array}$ & $\begin{array}{l}\text { Is there anything else you would like to say or add? } \\
\text { Age, gender, cancer diagnosis, number of people in household, occupation }\end{array}$ \\
\hline 5. Thank you & Debrief to include checking patient is happy with interview and using it in study, re-explain if necessary \\
\hline
\end{tabular}

Being organised and keeping records was described by three-quarters (18 out of 24). This included collecting and collating information on different HSCPs, contact details and locations as well as information on their condition and symptoms control, as illustrated with patient 21's filing system.

Everything is read, everything's replied to if it needs replying, and once it's finished with we put in a folder ...two files...one that's near finished unless somebody wants to ask a question...other one's relevant on what's happening now... (Patient 21)

Patient 21 contributed actively in managing his own care. Although quite recently diagnosed, he could utilise knowledge from a previous cancer experience, family who worked in a hospital and his own administrative skills and time resources as a retired manager.

Eighteen patients described some level of family involvement, 13 of whom had the major involvement of one specific family member, as illustrated below.

...I haven't got any information, my wife carries all that around with her...[wife] says...'I'll phone and do this'...'I'll see when she's coming'...she keeps it in her brain, mainly, about who's coming and...the medication I'm supposed to be getting... (Patient 20)

Patient 20's wife did most of the care management and communication work for him, probably demonstrating the advantage of knowledge gained working in healthcare herself.

How the system was organised could cause delays or additional work for patients unaware of how to negotiate direct access to care when needed, for example, by conveying their 'genuine status' or urgency to gatekeepers. Although limited in knowledge and experience initially, patient 8 had acquired this greater understanding in the 19 months since her diagnosis.

I phoned [GP]...'Can I have a doctor's appointment', and she said '...have a phone call back from the triage nurse'...[CNS]...said to me, '...Always let them know that you're under the [Palliative Care Unit]... (Patient 8)

Patient described challenges to their greater involvement and/or understanding; these are summarised in box 2 .

Many patients (21 out of 24) identified structural or organisational challenges that prevented them from understanding and contributing more actively to their care communication. A common challenge was the large number of HSPCs involved, and lack of clarity on lines of communication and responsibility, as the following examples illustrate.

...confusing, because I've got three sets of professionals, all of whom have the capability of making judgements as to what drugs I should be taking, or when I should be taking them... (Patient 2) 
Table 2 Main theme: patient work —involvement, strategies and project management and subthemes with examples from patient interviews

\begin{tabular}{|c|c|}
\hline Subtheme & Examples and descriptions \\
\hline Being organised and keeping records & $\begin{array}{l}\text { Keeping information all together somehow, for example, prescriptions receipts; letters; and } \\
\text { details of past appointments in bags, diaries, drawers, folders, big pile, etc } \\
\text { Making a record of appointment dates on a calendar or in the diary } \\
\text { - Creating a bespoke schedule of appointments } \\
\text { - Knowing how to get hold of information and contact details if needed }\end{array}$ \\
\hline Planning ahead and coordinating care & $\begin{array}{l}\text { Making the next appointment while at the current one } \\
\text { Rearranging appointment dates to coincide with each other or to enable another activity to } \\
\text { still take place } \\
\text { Planning ahead, eg, prescription refill and treatment dates }\end{array}$ \\
\hline Information gathering & $\begin{array}{l}\text { Drawing on previous experiences of cancer treatment } \\
\text { Using family with experience of healthcare context } \\
\text { Talking to other patients } \\
\text { Listening in to other people's conversations (eg, in waiting rooms, clinics, wards) } \\
\text { Following up conversations and asking questions } \\
\text { Seeking a second opinion } \\
\text { Keeping notes and lists of questions and answers }\end{array}$ \\
\hline Understanding the hierarchy/knowing who are key people & $\begin{array}{l}\text { Going straight to the person in charge } \\
\text { Using the medical secretary to communicate with the doctor } \\
\text { Seeking engagement with a senior manager } \\
\text { Using the nurse specialist to liaise with/gain answers from the oncology department } \\
\text { Trying another professional if getting nowhere with the first } \\
\text { Prioritising the people or teams involved at any one time } \\
\text { Asking for specific involvement of certain teams or people } \\
\text { Knowing who were the key decision makers within teams } \\
\text { Acknowledging the need to be 'available when busy professionals need you to be' } \\
\text { Being selective in terms of who was involved (eg, removing/excluding from network those } \\
\text { who were unhelpful or unreliable) }\end{array}$ \\
\hline Strategies to remember names and roles & $\begin{array}{l}\text { Making a general effort to remember names } \\
\text { - Writing names and roles down } \\
\text { Remembering faces, distinguishing features and ethnicity } \\
\text { Making up memorable nicknames or likening them to famous people } \\
\text { Focusing effort on remembering only names of selected people who lead a team or were } \\
\text { particularly helpful or powerful }\end{array}$ \\
\hline Understanding and 'working the system' & $\begin{array}{l}\text { Knowing 'how the system works' and who were best able to help them, such as } \\
\text { recognising the hierarchy within teams } \\
\text { Transporting messages, written communication between locations and care providers } \\
\text { Seeking continuity when making appointments to see health professionals } \\
\text { Being willing to forgo continuity in favour of timely care } \\
\text { Attempting to 'hurry up' doctor's appointments } \\
\text { Demonstrating frustration in their voice to get action } \\
\text { Conveying urgency or legitimacy by using the name of another person such as CNS, } \\
\text { consultant or the specialist palliative care unit } \\
\text { Not just waiting for someone to get back to them } \\
\text { Waiting 'long enough' and then initiating contact themselves } \\
\text { Knowing what needs to be done and 'just getting on with it' } \\
\text { Asking the same question repeatedly } \\
\text { Having the confidence to know when to call someone if need help } \\
\text { Being opportunistic, for example, taking any time offered to talk whenever they could get it } \\
\text { Being quick and precise in their own interactions with busy professionals } \\
\text { Making active attempts to ensure continuity of care by requesting the specific involvement } \\
\text { - Facilitating communication by asking professionals or family members to make contact on } \\
\text { their behalf with others also involved in their care network }\end{array}$ \\
\hline $\begin{array}{l}\text { Work on patients behalf: professionals and family work, } \\
\text { delegating or clarity from others }\end{array}$ & $\begin{array}{l}\text { Family phoning on patients behalf, explaining the situation for them to gatekeepers } \\
\text { Health professionals sharing and finding out information on behalf of the patient } \\
\text { Clear guidance from professionals on how to make contact directly or via gatekeepers } \\
\text { Being routinely kept up-to-date as decisions were made } \\
\text { Being copied into/sent copies of letters between consultants } \\
\text { Being given clear examples of possible (legitimate) reasons why they might want to call a } \\
\text { health professional }\end{array}$ \\
\hline
\end{tabular}

CNS, clinical nurse specialist. 
Box 2 Patient described reasons for any limited involvement or understanding in their care management and coordination

Not having routine access to own health records

- Having no obvious key worker or too many 'key' people involved to know whom to contact first

- Not knowing whom to contact if problems or about particular issues

- Things happening too quickly to influence them

Not knowing who they were going to see next

Not wanting to waste professionals' time

Just waiting for the letter to come

- Knowing that the person or team will contact them eventually

- Not wanting to voice or admit to any negative thoughts

Not wanting to ask for help for themselves

- Not wanting to contact a professional without 'good reason'

- 'Just doing what the doctor wants'

Not wanting to 'be a bother' or to 'make a fuss'

Unable or too unwell to influence things

Accept everything without question

Accept 'whatever the first person tells you'

...there's four District nurses up there...only one at a time...you don't know which one was coming. (Patient 4)

Half of the patients (12 out of 24) indicated reluctance to overstep some perceived boundary, disturb a busy HSCP and/or make 'a fuss'. Patients 12 and 23 are both female, over 75 years old, and have limited previous relevant health, family or work experiences to draw on.

I let them come to me...I don't want to be a pest and a bother... (Patient 12)

I've only seen [Nurse] once, and I don't know...she'll let me know when she's calling...I'm just waiting... patiently... (Patient 23)

Changes in care location, especially from inpatient to community, sometimes meant patients were unsure who to go to; plus information could be delayed, as patient 24 illustrates.

I was expecting to, when I left hospital...to have heard from somebody about what was going to happen next...phone the hospital ourselves to ask...I don't think it helps that there are several people involved...I've got the original surgeon, I've got...[ Surgeon from X], and I've got [Oncologist]...I've got no one person I go to... (Patient 24)

Patient 24 drew on her previous health experiences; plus her husband, like many family members, discussed and shared in much of the necessary background work required such as obtaining information, establishing legitimacy of concerns and negotiating access via gatekeepers.

A small minority of patients in this study appeared largely uninvolved and passive about trying to understand or contribute to managing the network of care surrounding them, mainly because they felt unable to or were too unwell. They either had family members doing this for them or were inpatients at the time of interview.

\section{DISCUSSION}

This study reveals some of the activity of patients and their family in contributing to the communication management of their care, some of it quite subtle and hidden.

Taking an active communication management role could be an additional burden for patients or family. However, if carried out effectively, it potentially reduces burden by helping in avoiding organisational delays, enhancing continuity and self-management, ${ }^{29}$ and minimising disruptions. ${ }^{22}$ Unfortunately, effort is often expended just to get the basic level of understanding required for effective contribution (eg, knowing names, roles, who to approach, best mode of contact, etc).

This study concurs with previous observations on the importance of patient/family activity in facilitating communication across care boundaries, ${ }^{18}$ the central role of the family in cancer care ${ }^{7}$ and expands our knowledge on the different forms this activity might take. The majority of patients in this study described some family involvement in practical communication management tasks, as well as background work in gaining knowledge, negotiating through gatekeepers and decision-making work on the legitimacy of queries - of whom to contact and how.

For a small number of patients, family took on all the organising and remembering of work on their behalf. It is unclear from this study who would perform this role if no family were willing and able to do this. With growing numbers of people living alone with cancer, especially older people,${ }^{30}$ this is a serious concern. HSCPs need to understand the challenges, and ascertain patients and families willingness and ability to undertake the work required, plus acknowledge resource differences in knowledge, time, etc. Patients/family gain understanding with time and experience, but for palliative care patients' capacity and time are usually diminishing resources. Table 3 summarises some suggestions on how HSCPs could help overcome the challenges.

\section{CONCLUSION}

Patients with palliative care needs often require a large care network to support them. This paper explores some of challenges, different levels of understanding and the often hidden background work undertaken by 
Table 3 Summary of suggested recommendations for clinical practice aimed at reducing patient burden and/or enhancing patient/family understanding

Issue/problem

Potential solution

Large care network

- Patient/family do not always know who everyone is and their roles or areas of responsibility

Patients and family can expend effort and time, background decision work on-

- Deciding if an issue is worth bothering HSCP and who is best to contact

- Finding out how to contact someone and negotiating access through gatekeepers such as medical secretaries, receptionists, switchboards, etc

- Deciding how long to wait before initiating contact

Patient role expectations

- Patients not wanting to be (or to be perceived as) 'making a fuss'

Available resources

- Some patients and family have more time, understanding (probably through work, previous experiences or family), organisational skills and confidence than others

- Patients who are unable or unwilling to take an active role and have no one doing it on their behalf; lack family members to share some of the background and decision-work

HSCP, health and social care professional.

patients and family in order to comprehend and contribute to their care management. Some ways HSCP can help are suggested.

Acknowledgements The authors are very grateful to the patients, family members and all the other people involved in patients' care who kindly gave their time to share their experiences. Thank you to Dimbleby Cancer Care Research Fund for funding this research project. With many thanks to the advisory group members, who comprise patients, carers, clinicians and academics, for their time, support and wisdom during all stages of the study. In particular, the authors would like to thank Helen Langhorn, Pip McMahon, Tricia Moate, Gaye Orr, Alan Parker and Bernadette Waters. Finally thank you to the two anonymous reviewers for their helpful comments.

Funding Dimbleby Cancer Care Research Fund.

Competing interests None.

Ethics approval REC Berkshire (ref 10/H0505/51).

Provenance and peer review Not commissioned; externally peer reviewed.

\section{REFERENCES}

1 Dawson S. Interprofessional working: communication, collaboration...perspiration! Int J Palliat Nurs 2007;13:502-5.

2 Walshe C, Caress A, Chew-Graham C, et al. Implementation and impact of the Gold Standards Framework in community palliative care: a qualitative study of three primary care trusts. Palliat Med 2008;22:736-43.

3 Kerstetter NC. A stepwise approach to developing and training an oncology multidisciplinary conference. Cancer Nurs 1990;13:216-20.

4 Wendt J. Case in point: case study: interdisciplinary hospice care team. Oncol Nurs Forum 1999;26:1279-80.

5 Boyle FM, Robinson E, Heinrich P, et al. Cancer: communicating in the team game. ANZ J Surg $2004 ; 74: 477-81$.
- HSCP regularly review with patients and family who is involved in the patient's care network and what they are responsible for, especially when the care location changes

- HSCP can provide examples and discuss different issues or questions a patient may have and who would be suitable to contact about this

- Ensure patient has contact details for those involved in their care or their gatekeepers. Explain how to speed up or skip gatekeepers, providing examples of when necessary

- Explain the usual expected length of time (between appointments, for results, etc) and what to do if not heard by then

- Explore with patient their expectations and provide examples of how patients or family can take more of an active role. Reassure regarding how this will be perceived by HSCP

- Assess differences in ability and willingness

- Find out patients/families understanding of the healthcare system, its hierarchy and communication routes

- Identify and instigate enhanced support and monitoring by HSCP
6 National Cancer Action Team. The characteristics of an effective multidisciplinary team (MDT). NHS February. 2010.

7 Ballard-Reisch DS, Letner JA. Centering families in cancer communication research: acknowledging the impact of support, culture and process on client/provider communication in cancer management. Patient Educ Couns 2003;50:61-6.

8 Farquhar MC, Barclay SIG, Earl H, et al. Barriers to effective communication across the primary/secondary interface: examples from the ovarian cancer patient journey (a qualitative study). Eur J Cancer Care 2005;14:359-66.

9 Negley KDF, Ness S, Fee-Schroeder K, et al. Building a collaborative nursing practice to promote patient education: an inpatient and outpatient partnership. Oncol Nurs Forum 2009;36:19-23.

10 Davis S, Kristjanson LJ, Blight J. Communicating with families of patients in an acute hospital with advanced cancer: problems and strategies identified by nurses. Cancer Nurs 2003;26:337-45.

11 Thorne SE, Bultz BD, Baile WF. Is there a cost to poor communication in cancer care? A critical review of the literature. Psychooncology 2005;14:875-84.

12 Trummel DE, McCabe KM, Cina SJ. Characteristics of hormone-treated prostate carcinoma: stressing the need for clinician-pathologist communication. Mil Med 2000;165:294-7.

13 Thorne SE, Hislop TG, Armstrong EA. et al. Cancer care communication: the power to harm and the power to heal? Patient Educ Couns 2008;71:34-40.

14 Rodin G, Mackay JA, Zimmerman C, et al. Clinician-patient communication: a systematic review. Support Care Cancer 2009;17:627-44.

15 Rodin G, Zimmerman C, Mayer C, et al. Clinician-patient communication: evidence-based recommendations to guide practice in cancer. Curr Oncol 2009;16:42-29. 
16 Hack TF, Degner LF, Parker PA. The communication goals and needs of cancer patients: a review. Psychooncology $2005 ; 14: 831-45$

17 King M, Jones L, Richardson A, et al. The relationship between patients' experiences of continuity of cancer care and health outcomes: a mixed-methods study. Br J Cancer 2008;98:529-36.

18 Kimberlin C, Brushwood D, Allen W, et al. Cancer patient and caregiver experiences: communication and pain management issues. J Pain Symptom Manage 2004;28:566-78.

19 Department of Health. Transfer of information across the interface between health care professionals and other agencies. Department of Health, 2003.

20 Gysels M, Richardson A, Higginson IJ. Does the patient-held record improve continuity and related outcomes in cancer care: a systematic review. Health Expect 2006;10:75-91.

21 Jarrett N. Patients' experiences of inter- and intra-professional communication (IIPC) in the specialist palliative care context. Int J Disabil Hum Dev 2009;8:51-8.

22 May C, Montori VM, Mair F. We need minimally disruptive medicine. BMJ 2009;339:B2803.

23 Department of Health. Cancer Reform Strategy. Department of Health, 2007.
24 Aubin M, Giguere AM, Verreault R, et al. Interventions to improve continuity of care in the follow-up of patients with cancer (Protocol). Cochrane Database Syst Rev 2012;7: CD007672.

25 Arora NK. Advancing research on patient-centered cancer communication. Patient Educ Couns 2008;70:301-2.

26 NHS Modernisation Agency Department of Health. Cancer services collaborative 'Improvement Partnership': improving communication in cancer care. Leicester: NHS Modernisation Agency, 2004.

27 National End of Life Care Programme. Record keeping guidance. March 2012.

28 Department of Health. End of life care strategy: promoting high quality care for all adults at the end of life. Department of Health, 2008.

29 McCorkle R, Ercolano E, Lazenby M, et al. Self-management: enabling and empowering patients living with cancer as a chronic illness. CA Cancer J Clin 2011;61:50-62.

30 Hanratty B, Addington-Hall J, Arthur A, et al. What is different about living alone with cancer in older age? A qualitative study of experiences and preferences for care. BMC Fam Pract 2013;14:22. 
BMJ

Supportive

$\&$ Palliative

Care
Palliative care patients' perceptions of the work involved in understanding and managing the network of care provision surrounding them

N Jarrett, K Porter, C Davis, J Lathlean, S Duke, J Corner and J Addington-Hall

BMJ Support Palliat Care published online March 31, 2015

Updated information and services can be found at:

http://spcare.bmj.com/content/early/2015/03/31/bmjspcare-2014-0007 81

\section{These include:}

References This article cites 24 articles, 1 of which you can access for free at: http://spcare.bmj.com/content/early/2015/03/31/bmjspcare-2014-0007 81\#BIBL

Email alerting Receive free email alerts when new articles cite this article. Sign up in the service box at the top right corner of the online article.

\section{Notes}

To request permissions go to:

http://group.bmj.com/group/rights-licensing/permissions

To order reprints go to:

http://journals.bmj.com/cgi/reprintform

To subscribe to BMJ go to:

http://group.bmj.com/subscribe/ 